\title{
A new perspective on the ecological effects of toxic weeds in grassland ecosystems
}

\author{
Zhenchao Zhang ${ }^{1}$, Jian $\mathrm{Sun}^{2}$, Miao Liu ${ }^{2}$, Ming Xu ${ }^{3}$, Yi Wang ${ }^{4}$, Gaolin $\mathrm{Wu}^{5}, \mathrm{H}$ Zhou ${ }^{6}$, \\ Chongchong $\mathrm{Ye}^{7}$, Tsechoe Dorji ${ }^{8}$, and Tianxing $\mathrm{Wei}^{1}$ \\ ${ }^{1}$ Beijing Forestry University \\ ${ }^{2}$ Institute of Geographic Sciences and Natural Resources Research, Chinese Academy of \\ Sciences \\ ${ }^{3}$ Rutgers University \\ ${ }^{4}$ Chengdu University of Technology \\ ${ }^{5}$ State Key Laboratory of Soil Erosion and Dryland Farming on the Loess Plateau of \\ Northwest Sci-Tech University of Agriculture and Forestry \\ ${ }^{6}$ Northwest Plateau Institute of Biology, Chinese Academy of Sciences \\ ${ }^{7}$ Institute of Geographic Sciences and Natural Resources Research Chinese Academy of \\ Sciences \\ ${ }^{8}$ Key Laboratory of Alpine Ecology and Biodiversity, Institute of Tibetan Plateau \\ Research, Chinese Academy of Sciences
}

May 5, 2020

\begin{abstract}
The sharp rise in anthropogenic activities and climate change have caused the extensive degradation of grasslands worldwide, jeopardising ecosystem function and threatening human well-being. Toxic weeds have been constantly spreading in recent decades; indeed, their occurrence is considered to provide an early sign of land degeneration. Policy makers and scientific researchers often focus on the negative effects of toxic weeds, such as how they inhibit forage growth, kill livestock and cause economic losses. However, toxic weeds can have several potentially positive ecological impacts on grasslands, such as promoting soil and water conservation, improving nutrient cycling and biodiversity conservation, and protecting pastures from excessive damage by livestock. We reviewed the literature to detail the adaptive mechanisms underlying toxic weeds and to provide new insight into their roles in degraded grassland ecosystems. The findings highlight that the establishment of toxic weeds may provide a self-protective strategy of degenerated pastures that does not require special interventions. Consequently, policy makers, managers and other personnel responsible for managing grasslands need to take appropriate actions to assess the long-term trade-offs between the development of animal husbandry and the maintenance of ecological services provided by grasslands.
\end{abstract}

\section{Foreword}

Toxic weeds refer to plants of secondary compounds which are toxic to livestock, wild herbivore, and human (James et al. 2005). Some toxic weeds accumulate toxins at high levels whose concentration can be influence by the inhabiting conditions (Zhao et al. 2013). The toxic principles mainly include toxic proteins, terpenoids, glycosides, alkaloids, polyphenols and photosensitive substances (Zhao et al.2013), which can be extracted and used as pesticides with remarkable pesticidal and antimicrobial activities (Zhang et al. 2011; Gaoet al. 2013; Chen et al. 2017). As important indicators of grassland degradation, toxic weeds have 
become increasingly global in their distribution in recent decades due to widespread grassland degradation (Sun et al. 2009; Zhao et al. 2010; Zhaoet al. 2013; Wu et al. 2016). Furthermore, a longer growing season and warming induced by climate change will intensify the increases in the occurrence and production of toxic weeds (Klein, Harte \& Zhao 2007; Ziska, Epstein \& Schlesinger 2009).

Statistically, there are approximately 1300 toxic species covering approximately $33.3 \mathrm{~m}$ ha in China's natural grasslands (Shi \& Wang 2004; Zhao et al. 2010). They have been traditionally thought that the wide distribution of toxic weeds leads to pasture degeneration and thereby reductions of grassland forage availability (Zhao et al.2013; Wu et al. 2016). Additionally, poisonous weeds not only damage livestock breeding (Panter et al. 1999) but also poison - or even kill - domestic animals if they are ingested by accident or if the pollen is inadvertently inhaled (Braun et al.2003; Zhao et al. 2013), potentially resulting in substantial economic losses and hindering the sustainable development of the livestock industry. It is estimated that toxic-weed poisoning results in direct or indirect economic losses of billions of CNY in China each year (Shi 2001). The reduced grazing capacity and economic losses induced by toxic weed lead to lower resilience and increase in vulnerability of livelihoods that depend on livestock. Therefore, numerous approaches have been employed to control the spread of toxic weeds (Lu et al. 2012; Stokstad 2013). However, most techniques have done little to eradicate established plants, and some approaches may even have negative environmental effects (Stokstad 2013; Boutin et al. 2014).

In fact, the spread of toxic weeds is not the reason for grassland degradation but a consequence of their strong adaptive capacity. Toxic weeds often have long and well-developed root systems to facilitate the capture of water and nutrients from deep soil profiles (Sun et al. 2014), inhibit the growth of co-occurring plants via allelopathy (Yan et al. 2016), form intraspecific aggregations that enhance their ability to compete with heterospecific competitors (Ren, Zhao \& An 2015), and are not exposed to selection by livestock and small rodents (Zhao et al. 2013). From an ecological perspective, the colonization of toxic weeds can be more beneficial than harmful by promoting the process of succession in degraded grasslands by excluding excessive disturbance from livestock (Cheng et al. 2014b). An improved understanding of the potential role of toxic weeds in grassland conservation will challenge the traditional view that toxic weeds are uniformly deleterious and will enable pasture managers and policy makers to modify and design more flexible strategies for addressing global change and promoting sustainability. Here, we conduct a review of the literature to detail the fitness and potential effects of toxic weeds. These findings provide novel insight into the adaptive management of weed-dominated grasslands.

\section{Adaptation of toxic weeds}

In addition to the effects of natural factors, such as soil physiochemical properties and topographical conditions (Hou et al. 2013; Li et al. 2013), toxic weeds are most commonly a product of overgrazing and grassland degeneration. The population gradually increases and becomes dominant in plant communities as grassland degradation and grazing intensity increases (Zhang, Yue \& Qin 2004; Zhang et al. 2004; Li, Jia \& Dong 2006; Wang et al.2016; Ricciardi et al. 2017). This pattern is likely mostly due to that toxic weeds have various adaptive strategies for environmental stress and anthropogenic disturbance including higher genetic variation, well-developed roots, allelopathy effect, and poisonous for herbivores.

\subsection{Strategies of adaptation to the environment}

A large number of toxic weeds are long-lived perennial species with self-incompatible mating systems and therefore generally have high quantities of genetic variation, which facilitates adaptive evolution to various environmental conditions and contributes to their wide geographic distribution (Ghalambor et al. 2007; Zhang et al. 2015b; Bruijning et al. 2019). For example, Stellera chamaejasme inhabits a wide range of altitudes from 130 to $4200 \mathrm{~m}$, including the North China Plain, the Inner Mongolia Plateau and the Tibetan Plateau, as well as a wide area from southern Russia to southwest China and the western Himalayas, which is suggestive of high adaptability (Liu, Long \& Yao 2004; Wang 2004; Wang \& Gilbert 2007; Zhang, Volis \& Sun 2010; Zhao et al. 2010) (Fig. 1). The various morphological and physiological traits of toxic weeds promote increases in the fitness to harsh environments, such as drought, cold or barren soils (Wong et al. 
2004; Kraft et al. 2015; Wang et al. 2016). As shown in Fig. 2, leaves of these weeds are often lanceolate with thick waxy layers that tolerate prolonged drought conditions (Dou, Feng \& Hou 2013). Moreover, many toxic weeds can capture water and nutrients from deeper soil profiles via their long and deeply distributed roots (Sun et al. 2009). Additionally, rhizobacteria has been found to stimulate the growth of these weeds by optimizing nutrient supplies and promoting plant metabolism and systemic resistance under unsuitable growth conditions (Lugtenberg \& Kamilova 2009; Lehmann et al. 2011; Cui et al. 2015; Hui et al. 2018). Endophytic bacteria also make toxic weeds more tolerant to abiotic stress (Sieber 2007; Hyde \& Soytong 2008; Jin et al. 2014) .

Toxic weeds follow the optimal partitioning rule wherein plants partition photosynthate among their various organs to maximise growth rate in different habitats (Chapin et al. 1987). For example, some toxic weeds have been observed to allocate more biomass to hydrotropic roots under drought stress (Sun et al. 2014). In addition, plant body size decreases at higher elevations to reduce nutritional needs in less resource-rich environments; however, more photosynthetic products are allocated to flowers at higher elevations to enhance reproductive success (Zhang et al. 2013). High altitudes make toxic weeds produce fewer, but larger, flowers with colour polymorphisms to attract pollinators in adverse environments (Zhanget al. 2013; Zhang et al. 2015a) where low temperatures and strong winds discourage insect activity (Zhang, Zhang \& Sun 2011). On the other hand, the number of branches on toxic weeds is reduced and plant height is increased in north-facing compared with south-facing slopes, suggesting that toxic weeds allocate more photosynthate to vertical growth than to horizontal growth in response to competition for light (Hou et al. 2014). The physiological responses of toxic weeds also show signatures of adaptation to resource-constrained conditions. For example, toxic weeds have higher proline concentrations and rates of water use in south-facing slopes with arid environments (Liu \& Ma 2010; Hou, Liu \& Sun 2017). However, toxic weeds in north-facing slopes with weaker light intensities have higher chlorophyll contents and photosynthetic efficiencies (Liu et al.2017).

\subsection{Interspecific relationships}

Owing to their wide niche breadth, toxic weeds can successfully coexist with several other plant species (Ren, Zhao \& An 2013; Cheng et al.2014a). Unlike the shallow-rooted graminoids whose roots horizontally extend in the surface soil (Wang et al. 2004), toxic weeds are mostly axial-root species which deeply root, and thus can absorb water and nutrients from much deeper in the soil compared to forages (Li, Niu \& Du 2011; Maguire, Sforza \& Smith 2011; Sun et al. 2014). Such interspecific differentiation in the acquisition of soil resources alleviates competition and permits co-existence with heterospecific plants (Fargione \& Tilman 2006; Ryel 2010; Xin et al. 2012). Nevertheless, perennial toxic weeds are usually tall and thus superior competitors for light resources relative to shorter plant species (Hautier, Niklaus \& Hector 2009; Craine \& Dybzinski 2013; Li et al. 2016). In addition, individuals often aggregate to form patches that facilitate intraspecific cooperation, enhance their competitive ability and promote their expansion (Sun, Ren \& He 2011; Gao \& Zhao 2013; Ren, Zhao \& An 2015). As a consequence, patches of heterospecific plants that are separated by toxic weeds often are not able to survive in the presence of competitively superior toxic weeds (Zhao et al. 2016).

The allelopathy of toxic weeds is an important competitive behaviour that inhibits the growth of receptor plants (Fig. 3). The primary phytotoxic mechanisms are regulated via the following two pathways. First, allelochemicals (e.g. flavonoids, coumarins and phenolic compounds) can inhibit mitosis (Yan et al. 2016), reduce chlorophyll content (Pan et al. 2015), disrupt root development (Yan et al. 2014), promote the overproduction of proline (Yanet al. 2016), inhibit germination (Cheng et al. 2011), reduce endogenous auxin content (Yang et al. 2011), and promote reactive oxygen species accumulation (Pan et al. 2015; Yanet al. 2015). The second pathway is the arrest of sexual multiplication by pollen allelopathy (Sun, Luo \& $\mathrm{Wu}$ 2010). Interestingly, phytotoxic effects increase with age; that is, older plants are superior competitors compared with younger plants (Weiet al. 2017). Notably, the allelopathy effects of toxic weeds exhibit species specificity, for example, S. chamaejasme has strong inhibitive effects on some species including Setaria viridis, Amaranthus retroflexus (Pan et al. 2015),Pedicularis kansuensis (Hou et al. 2011), Festuca rubra L. , Medicago sativa (Guo et al. 2015), Melilotus suaveolens Ledeb (Wang, Zhou \& Huang 2009) 
and Onobrychis viciifolia (Zhou et al. 2009b), while other species such as Agropyron mongolicum (Wang et al. 2008),Psathyrostachys juncea (Zhou et al. 2009a), Elymus dahuricus (Zhou et al. 2010) and Lolium perenne (Wang, Zhou \& Huang 2009) show resistibility against the allelopathy effect ofS. chamaejasme . Therefore, these species can be used to restore degraded grasslands inhabited by toxic weed.

\subsection{Defensive strategies against animals}

Toxic weeds are more resistant to grazing than grasses favoured by herbivores, especially when available forage is limited (Ren et al. 2016). Indeed, the niche breadth of toxic weeds is enhanced under grazing (Mou et al. 2013), but they also exhibit superior tolerance to physical breakdown because of their tenacious capacity to regenerate once damaged ( $\mathrm{Li}$ et al. 2008). Endophytic fungi can protect plants from nematodes, insect pests and fungal pathogens (Barillas et al. 2007; Jin et al. 2013). Furthermore, the toxic components of these weeds are capable of poisoning or killing small rodents and play a vital role in protecting toxic weeds from animals and pathogens (Yan et al. 2015). The content of toxic substances is highest in leaves, which is the vegetative organ most likely to be consumed by herbivores. Furthermore, the content of toxic substances dramatically increases in response to trampling and consumption by livestock, which reduces the grazing intensity on toxic weeds (Zheng \& Hu 2006). The texture and colour of toxic weeds are also striking (Fig. 2 ), which likely aid the identification, recognition and classification of toxic weeds by animals as distasteful and indigestible food items.

In response to long-term overgrazing and selective foraging, palatable grasses become miniaturised, restricting their ability to utilize natural resources. However, the ecological niche of toxic weeds also widens through increases in the number of reproductive branches and individual florets (Han et al. 2006). The grazinginduced reduction of interspecific competition also contributes to the dominance of toxic weeds in plant communities (Ren et al. 2016). In addition to grazing duration, grazing intensity also affects the distribution of toxic weeds, which often aggregate when grazing is intense but are randomly distributed when grazing is especially intense (Xing \& Song 2002; Zhao et al. 2011). Thus, the intraspecific relationship shifts from being mutualistic to competitive depending on the intensity of grazing (Ren \& Zhao 2013).

Reproductive strategies of toxic weeds with high survival rates include floral traits, such as the brilliant terminal flower head (Fig. 2D), which increases reproductive success by attracting pollinators (Jameset al. 2005; Zhang, Zhang \& Sun 2011). Additionally, the seeds are hard and durable and the seedlings are capable of exploiting grazed areas with reduced competition from palatable grasses (Zhao et al. 2013). The proportion of old plants in grasslands increases with grazing intensity. In addition, old individuals have a higher fecundity and produce larger quantities of seeds compared with younger plants (Xing, Gou \& Wei 2004). Thus, the breadth and density of the soil seed bank increases as the intensity of grassland degradation rises, enhancing the ability of the population to regenerate (Zhao \& Zhang 2010; Du et al. 2015).

\section{Potential ecological effects of toxic weeds}

Traditionally, toxic weeds are not only thought to cause economic losses to livestock production but are also thought to do great harm to grasslands and lead to their degradation (James et al. 2005; Luet al. 2012; Zhao et al. 2013). However, this parochial view may neglect the manifold ecological roles that toxic weeds can play as important natural components of grassland ecosystems. For instance, toxic weeds can provide a number of ecological, social and economic benefits by improving soil quality, protecting forage resources and promoting the sustainable development of grasslands.

\subsection{Effects on soils}

Regarding soil and water conservation, the well-developed root systems of toxic weeds can fix sand and capture nutrients from soils with coarser textures (Wang 2001; Wong et al. 2004). As we know, grazing and grassland degradation induce reversed vegetation succession with deterioration of plant community structure from palatable grasses to toxic weeds (Wang et al. 2009; Wu et al. 2009). Even so, compared to bare land, grassland covered by toxic weeds is more susceptible to erosion from strong wind and rain (Zhang, Yue \& Qin 2004). On the other hand, toxic weeds significantly increase the water content of the soil surface under 
drought conditions (An et al.2016). The higher coverage of plants shields topsoil from solar radiation and decreases evaporation (Mchunu \& Chaplot 2012); moreover, the soil infiltration rate is relatively high as a result of a well-developed root system, stimulating rainfall storage (Song et al. 2018).

In addition to the physical protection that they provide to grasslands, toxic weeds have remarkable effects on soil nutrient pools and can create fertile islands (Sun et al. 2009) (Fig. 4). Toxic weeds produce more litter as a consequence of their increased growth and because they lose less tissue through grazing. Toxic weeds are also more labile and have higher tissue nitrogen and lower lignin nitrogen compared with other species (An et al. 2016). Soil microorganisms also contribute to the turnover rate and nutrient availability. Soil microbial biomass and soil enzyme activities are higher in toxic weed patches than in areas between these patches (An et al. 2016). Overall, the protection and improvement of soil by toxic weeds provide a superior material basis for plant growth and benefit the recovery of degraded grasslands.

\subsection{Effects on co-occurring plants}

It is commonly believed that toxic weeds have negative effects on the quantity of forage via allelopathy, thereby decreasing grassland productivity (Pan et al. 2015). However, toxic weeds actually provide biotic refuges and keep surrounding herbaceous species away from livestock in overgrazed grasslands (Fig. 4). The number of species and the coverage of neighbouring plants are noticeably higher in plots with toxic weeds than in those in open grasslands (Cheng et al.2014b). There are two principal means by which toxic weeds can facilitate the proliferation of neighbouring plants in overgrazed pastures. First, the toxic smell could repel livestock and thus reduce the ingestion and trampling of edible forage surrounded by toxic weeds (Oesterheld \& Oyarzabal 2004). Second, toxic weeds alter the surrounding micro-environmental conditions. For example, toxic weeds can redistribute soil nutrients, form fertility islands (Sun et al.2009) and create a cool environment that promotes soil moisture retention via the height of the plant canopy (Rebollo, Milchunas \& Chapman 2002). All of these micro-environmental changes provide better soil conditions and microclimates for plant growth. Additionally, the niche overlap between toxic weeds and fine herbage is smaller than that between toxic weeds and unpalatable weeds, reflecting the lower degree of competition between toxic weeds and edible forage (Ren, Zhao \& An 2013).

\subsection{Potential ecological roles in degraded grasslands}

From a successional perspective, the spread of toxic weeds is a consequence of their high adaptability rather than a cause of grassland degeneration. As an important part of the grassland ecosystem, toxic weeds improve plant community structure in degraded pastures (Tan \& Zhou 1995) and play a crucial role in preventing further desertification of degraded grasslands (Wang et al. 2016). Animals usually avoid poisonous toxic weeds, which inherently suppresses excessive disturbance by livestock when overgrazing occurs. The unfounded removal of toxic weeds might lead to ecosystem collapse (Fig. 5) because grazing pressure on pasture is greater without the protection that toxic grasses provide (Wang et al. 2014). This hypothesis is potentially consistent with previous studies that report that the degree of degradation of mowed grasslands was greater than that of grazed grasslands inhabited by toxic weeds (Wang \& Gilbert 2007; Li et al. 2008).

Furthermore, the presence of toxic weeds provides an essential means by which the coverage of vegetation can be maintained and the ecological functions of degraded grassland can be preserved (Fig. 5), although these should be considered some of their "better-than-nothing" effects. Toxic weeds provide an important gene pool, and their invasion increases the diversity of insects and invertebrates, facilitating the maintenance of biodiversity (Sun et al. 2013). Consequently, degenerated grassland with toxic weeds do not require any special interventions aside from controlling grazing intensity or limiting the overgrowth of toxic weeds. In support of these effects, the occurrence of toxic weeds is inhibited by the absence of grazing (Ren et al.2016). The potential process and underlying mechanism are as follows: First, residual yak dung deposition accelerates the proportional increase in graminoids and promotes the transformation of grasslands to gramineous communities following the exclusion of grazing (Mou et al. 2013). Moreover, grasses will recolonise and regain prevalence due to the maintenance of local genetic variation and because they can regenerate rapidly through the production of a large number of seeds (Liu \& Ma 2010; Cheng et al. 2014b). Finally, degraded 
grassland ecosystems will eventually be restored and become prosperous again following a long period of self-healing (Fig. 5).

\section{Conclusion and future prospects}

As a barometer of grassland health, the wide distribution of toxic weeds worldwide indicates that land degradation is a serious issue that threatens the sustainable developmental goal of "no poverty, zero hunger" of the Food and Agriculture Organization of the United Nations. This review provides an understanding of the adaptive abilities of toxic weeds and presents a new interpretation of their role in degenerated grassland ecosystems. Here, we argue that toxic weeds can provide self-protective mechanisms of degraded pastures and promote their resilience. In some cases, taking no action might be superior to taking actions that end up doing more harm than good. The blind removal of toxic weeds through the promotion of increased grazing will likely expose pastures to excessive damage, jeopardizing ecosystem balance. Thus, robust grassland management requires policy makers, managers and other personnel to continuously monitor and evaluate the long-term trade-offs between the development of livestock farming and the maintenance of multiple ecological services. An improved understanding of toxic weeds is valuable for the sustainable management of grasslands and for meeting the 2030 Global Land Degradation Neutrality Target set by the United Nations Convention to Combat Desertification (Tothet al. 2018).

\section{Author Contributions: Z.C.Z. and J.S. conceived the study. Z.C.Z., J.S., M.L., M.X., Y.W., G.L.W., H.K.Z. wrote the manuscript, Z.C.Z., J.S., M.L., M.X., Y.W., G.L.W., H.K.Z., C.C.Y., T.X.W. reviewed and revised the manuscript.}

\section{Acknowledgements}

Funding was provided by the State Key Research Development Program of China (Grant No. 2016YFC0501803 and 2016YFC0501802), the Second Tibetan Plateau Scientific Expedition and Research (Grant No.2019QZKK0405), and the Open Project of the Qinghai Provincial Key Laboratory of Restoration Ecology in Cold Area(2020-KF-05). We gratefully acknowledge the Beijing Municipal Education Commission for their financial support through Innovative Transdisciplinary Program "Ecological Restoration Engineering".

\section{Data availability}

All data included in this study are available upon request by contact with the corresponding author.

\section{Competing interests}

The authors declare no competing interests.

\section{References}

An, D.-Y., Han, L., Ju-Ying, W.U., Chen, J., Jiang, Y.Y., Liu, Y., Wang, Q.H. \& Amp, B. (2016) Effects of Stellera chamaejasme on Soil Properties of Grassland in Farming-pastoral Zone in North China.Acta Agrestia Sinica.

Barillas, J.R.V., Paschke, M.W., Ralphs, M.H. \& Child, R.D. (2007) White locoweed toxicity Is facilltated by a fungal endophyte and nitrogen-fixing bacteria. Ecology, 88, 1850-1856. 
Boutin, C., Strandberg, B., Carpenter, D., Mathiassen, S.K. \& Thomas, P.J. (2014) Herbicide impact on nontarget plant reproduction: what are the toxicological and ecological implications? Environmental Pollution, 185, 295-306.

Braun, K., Romero, J., Liddell, C.M. \& Creamer, R. (2003) Production of swainsonine by fungal endophytes of locoweed. Fungal Biology,107, 980-988.

Bruijning, M., Metcalf, C.J.E., Jongejans, E. \& Ayroles, J.F. (2019) The Evolution of Variance Control. Trends in Ecology 85 Evolution .

Chapin, F.S., Bloom, A.J., Field, C.B. \& Waring, R.H. (1987) Plant Responses to Multiple Environmental FactorsPhysiological ecology provides tools for studying how interacting environmental resources control plant growth. BioScience, 37, 49-57.

Chen, Q., Gao, T.T., Bo, L.I., Zha, Y.M., Tao, K., Jing, H. \& Hou, T.P. (2017) Studies on the mechanism of Stellera chamaejasme L.to Locusta migratoria manilensis(Meyen). Journal of Sichuan University .

Cheng, L.X., Chen, K.L., Yang, S.B., Xu, S.U. \& Wang, J.M. (2014a) Interspecific relations among the plants at Xiaopohu Wetland of eastern Qinghai Lake. Arid Land Geography, 37, 1005-1011.

Cheng, W., Sun, G., Du, L.F., Wu, Y., Zheng, Q.Y., Zhang, H.X., Liu, L. \& Wu, N. (2014b) Unpalatable weed Stellera chamaejasme L. provides biotic refuge for neighboring species and conserves plant diversity in overgrazing alpine meadows on the Tibetan Plateau in China.Journal of Mountain Science, 11, 746-754.

Cheng, X.Y., Yuan, H., Ren, G.H., Deng, B., Zhao, J.X. \& Shang, Z.H. (2011) Allelopathic effects of aqueous extracts from "Black Soil Patch" poisonous weeds on Elymus nutans in degraded alpine meadow. Acta Botanica Boreali-occidentalia Sinica , 2057-2064.

Craine, J.M. \& Dybzinski, R. (2013) Mechanisms of plant competition for nutrients, water and light. Functional Ecology, 27,833-840.

Cui, H.Y., Yang, X.Y., Lu, D.X., Jin, H., Yan, Z.Q., Chen, J.X., Li, X.Z. \& Qin, B. (2015) Isolation and characterization of bacteria from the rhizosphere and bulk soil of Stellera chamaejasme L. Canadian Journal of Microbiology, 61, 171-181.

Dou, H.J., Feng, L.I. \& Hou, Y.Y. (2013) Research advance in Wolfsbane and Stellera chamaejasme L. Animal Husbandry $\&$ Feed Science .

Du, J., Zhao, C.Z., Song, Q.H. \& Shi, Y.C. (2015) Spatial heterogeneity analysis of soil seed bank for degraded grassland Stellera chamaejasme populations based on geostatistics. Chinese Journal of Ecology,34, 94-99.

Fargione, J. \& Tilman, D. (2006) Plant species traits and capacity for resource reduction predict yield and abundance under competition in nitrogen-limited grassland. Functional Ecology, 20,533-540.

Gao, F.Y. \& Zhao, C.Z. (2013) Pattern-controlling mechanics of different age classes of Stellera chamaejasme population in degraded alpine grassland. Acta Ecologica Sinica, 33, 3114-3121.

Gao, M.L., Lang, W.U., Chen, L., Zhou, W., Tao, K. \& Hou, T.P. (2013) Bioactivity and histopathology study of the active ingredients from Stellera chamaejasme L. against Locusta migratoria manilensis(Meyen). Journal of Sichuan University .

Ghalambor, C.K., Mckay, J.K., Carroll, S.P. \& Reznick, D.N. (2007) Adaptive versus non-adaptive phenotypic plasticity and the potential for contemporary adaptation in new environments. Functional Ecology,21, 394-407.

Guo, H.R., Cui, H.Y., Hui, J., Yan, Z.Q., Lan, D. \& Bo, Q. (2015) Potential allelochemicals in root zone soils of Stellera chamaejasme L. and variations at different geographical growing sites. Plant Growth Regulation, 77, 335-342. 
Han, Y.J., Chen, G.C.Z., G. Y., Sun, J. \& li, J.P. (2006) Study on Morphological Response of the Alpine Steppes Plant Individuals to Grazing Stress. Journal of the Graduate School of the Chinese Academy of Sciences .

Hautier, Y., Niklaus, P.A. \& Hector, A. (2009) Competition for Light Causes Plant Biodiversity Loss After Eutrophication. Science, 324, 636-638.

Hou, Y., Chen, X.Y., Ren, G.H., Du, B. \& Shang, Z.H. (2011) Allelopathic effects of the typical Black Soil Land poisonous plant on Pedicularis kansuensisin Qinghai-Tibetan Plateau. Acta Botanica Borealioccidentalia Sinica, 31, 1651-1656.

Hou, Y., Liu, M.X. \& Sun, H.R. (2017) Response of plant leaf traits to microhabitat change in a subalpine meadow on the eastern edge of Qinghai-Tibetan Plateau,China. Chinese Journal of Applied Ecology, 28, 71-79.

Hou, Z.J., Zhao, C.Z., Li, Y., Zhang, Q. \& Ma, X.L. (2013) Responses of the spatial pattern of Stellera chamaejasme's aboveground biomass to topography in degraded alpine grassland. Chinese Journal of Ecology, 32, 253-258.

Hou, Z.J., Zhao, C.Z., Yu, L.I., Qian, Z. \& Ma, X.L. (2014) Trade-off between height and branch numbers in Stellera chamaejasme on slopes of different aspects in a degraded alpine grassland. Chinese Journal of Plant Ecology, 38, 281-288.

Hui, J., Yang, X.Y., Liu, R.T., Yan, Z.Q., Li, X.D., Li, X.Z., Su, A.X., Zhao, Y.H. \& Bo, Q. (2018) Bacterial community structure associated with the rhizosphere soils and roots of Stellera chamaejasme L. along a Tibetan elevation gradient. Annals of Microbiology, 68,1-14.

Hyde, K.D. \& Soytong, K. (2008) The fungal endophyte dilemma.Fungal Diversity, 33, 163-173.

James, L.F., Gardner, D.R., Lee, S.T., Panter, K.E., Pfister, J.A., Ralphs, M.H. \& Stegelmeier, B.L. (2005) Important Poisonous Plants on Rangelands. Rangelands, 27, 3-9.

Jin, H., Yan, Z.Q., Liu, Q., Yang, X.Y., Chen, J.X. \& B., Q. (2013) Diversity and dynamics of fungal endophytes in leaves, stems and roots of Stellera chamaejasme L. in northwestern China. Antonie Van Leeuwenhoek, 104, 949-963.

Jin, H., Yang, X.Y., Yan, Z.Q., Liu, Q., Li, X.Z., Chen, J.X., Zhang, D.H., Zeng, L. \& Qin, B. (2014) Characterization of rhizosphere and endophytic bacterial communities from leaves, stems and roots of medicinal Stellera chamaejasme L. Systematic and Applied Microbiology, 37, 376-385.

Klein, J.A., Harte, J. \& Zhao, X.Q. (2007) Experimental warming, not grazing, decreases rangeland quality on the Tibetan Plateau.Ecological Applications, 17, 541-557.

Kraft, N.J.B., Adler, P.B., Godoy, O., James, E.C., Fuller, S. \& Levine, J.M. (2015) Community assembly, coexistence and the environmental filtering metaphor. Functional Ecology,29, 592-599.

Lehmann, J., Rillig, M.C., Thies, J., Masiello, C.A., Hockaday, W.C. \& Crowley, D. (2011) Biochar effects on soil biota - A review. Soil Biology \& Biochemistry, 43, 1812-1836.

Li, A., Niu, K.C. \& Du, G.Z. (2011) Resource availability, species composition and sown density effects on productivity of experimental plant communities. Plant and Soil, 344, 177-186.

Li, J.Z., Liu, Y.M., Mo, C.G., Wang, L. \& Cao, M.M. (2016) IKONOS image-based extraction of the distribution area of Stellera chamaejasme L. in Qilian County of Qinghai Province, China. Remote Sensing,8, 148.

Li, X.D., Jiang, D.M., Li, X.H., Ji, L.Z., Luo, Y.M. \& Wang, H.M. (2008) A comparative study on biological traits of Stellera chamaejasme population under grazing and mowing conditions. Journal of Arid Land Resources E Environment. 
Li, X.R., Jia, X.H. \& Dong, G.R. (2006) Influence of desertification on vegetation pattern variations in the cold semi-arid grasslands of Qinghai-Tibet Plateau, North-west China. Journal of Arid Environments, 64, 505-522.

Li, Y., Zhao, C.Z., Dong, X.G., Hou, Z.J., Ma, X.L. \& Zhang, Q. (2013) Twig and leaf trait differences in Stellera chamaejasme with slope in alpine grassland. Chinese Journal of Plant Ecology, 37,709-717.

Liu, M., Zhao, R., Zhang, C., Li, R. \& Shao, P. (2017) Responses of physiological parameters in plants on sub-alpine meadow to slope aspects. Chinese Journal of Applied Ecology, 28,2863-2869.

Liu, M.X. \& Ma, J.Z. (2010) Study on proline accumulation patterns of six plant species under adversity stress. Pratacultural Science,27, 134-138.

Liu, Y., Long, R.J. \& Yao, T. (2004) Research progress on Stellera chamaejasme L. in grassland. Pratacultural Science.

Lu, H., Wang, S.S., Zhou, Q.W., Zhao, Y.N. \& Zhao, B.Y. (2012) Damage and control of major poisonous plants in the western grasslands of China - a review. Rangeland Journal, 34, 329-339.

Lugtenberg, B. \& Kamilova, F. (2009) Plant-growth-promoting rhizobacteria. Annual Review of Microbiology, 2009,541-556.

Maguire, D., Sforza, R. \& Smith, S.M. (2011) Impact of herbivory on performance ofVincetoxicumspp., invasive weeds in North America.Biological Invasions, 13, 1229-1240.

Mchunu, C. \& Chaplot, V. (2012) Land degradation impact on soil carbon losses through water erosion and $\mathrm{CO}_{2}$ emissions. Geoderma, 177-178, 72-79.

Mou, X.M., Yu, Y.W., Zhang, H.M., Sun, H., Wang, H.C., Xu, C.L., Chang-Lin, X.U. \& Hua, L.M. (2013) Effects of yak dung deposition on community characteristics and niche parameters in alpine meadow.Pratacultural Science, 30, 1594-1601.

Oesterheld, M. \& Oyarzabal, M. (2004) Grass-to-grass protection from grazing in a semi-arid steppe. Facilitation, competition, and mass effect. Oikos, 107, 576-582.

Pan, L., Li, X.Z., Yan, Z.Q., Guo, H.R. \& Qin, B. (2015) Phytotoxicity of umbelliferone and its analogs: Structureeactivity relationships and action mechanisms. Plant Physiology 83 Biochemistry, 97,272-277.

Panter, K.E., James, L.F., Stegelmeier, B.L., Ralphs, M.H. \& Pfister, J.A. (1999) Locoweeds: effects on reproduction in livestock. Journal of Natural Toxins, 8, 53.

Rebollo, S., Milchunas, D.-M.I. \& Chapman, P.L. (2002) The role of a spiny plant refuge in structuring grazed shortgrass steppe plant communities. Oikos, 98, 53-64.

Ren, H. \& Zhao, C.Z. (2013) Spatial pattern and competition relationship of Stellera chamaejasme and Aneurolepidium dasystachys population in degraded alpine grassland. Acta Ecologica Sinica,33, 435-442.

Ren, H., Zhao, C.Z. \& An, L.J. (2013) Niche characteristics of 'noxious and miscellaneous grass type'degraded grassland on northern slope of Qilian Mountains,China. Chinese Journal of Ecology, 32,2711-2715.

Ren, H., Zhao, C.Z. \& An, L.J. (2015) Spatial point patterns of Stellera chamaejasme and Stipa krylovii populations in degraded grassland of Noxious and Miscellaneous types based on Ripley's K(r) function. Journal of Arid Land Resources $\& 3$ Environment,29, 59-64.

Ren, J., Li, Y.J., Ouyang, Q., Ma, X. \& Dai, W. (2016) Effects of short-term enclosure and cattle dung on plant community composition and biomass of sub-alpine meadow. Acta Agrestia Sinica, 24,1197-1202.

Ricciardi, A., Blackburn, T.M., Carlton, J.T., Dick, J.T.A., Hulme, P.E., Iacarella, J.C., Jeschke, J.M., Liebhold, A.M., Lockwood, J.L. \& Macisaac, H.J. (2017) Invasion science: a horizon scan of emerging challenges and opportunities. Trends in Ecology and Evolution,32, 464-474. 
Ryel, R. (2010) Functional differences in water-use patterns of contrasting life forms in great basin steppelands. Vadose Zone Journal, 9, 548-560.

Shi, Z. (2001) The Important Poisonous Plant in China . China Agriculture Press, Beijing.

Shi, Z.C. \& Wang, Y.Z. (2004) Advances in the study of poisonous plants in the western grasslands of China. Chinese Journal of Biological Control, 20, 22-25.

Sieber, T.N. (2007) Endophytic fungi in forest trees: are they mutualists? Fungal Biology Reviews, 21, 75-89.

Song, A.Y., Dong, L.S., Liu, S.R. \& Liu, J.T. (2018) Soil infiltration characteristics and its influencing factors in different subalpine meadow communities. Research of Soil 83 Water Conservation,25, 41-45.

Stokstad, E. (2013) The War Against Weeds Down Under. Science,341, 734-736.

Sun, G., Luo, P. \& Wu, N. (2010) Pollen allelopathy of Stellera chamaejasme on pollen germination and seed set of main species in a High-frigid Meadow on the Eastern Qinghai-Tibetan Plateau. Acta Ecologica Sinica, 30, 4369-4375.

Sun, G., Luo, P., Wu, N., Qiu, P.F., Gao, Y.H., Chen, H. \& Shi, F.S. (2009) Stellera chamaejasme L. increases soil $\mathrm{N}$ availability, turnover rates and microbial biomass in an alpine meadow ecosystem on the eastern Tibetan Plateau of China. Soil Biology \& Biochemistry,41, 86-91.

Sun, J., Wang, X.D., Cheng, G.W., Chen, Y.C. \& Fan, J.H. (2014) Hydrotropism of Stellera chamaejasme Roots and Its Response to the Deposition of Ephemeral Stream along a Hillslope. Mountain Research, 32, 444-452.

Sun, T., Chen, Q., Zhao, Y.X. \& Long, R.J. (2013) Effects of invasive weeds on relative grasshopper abundance in alpine steppe in the Qilian Mountains. Acta Pratacultural Science, 22, 85-91.

Sun, Y.P., Ren, H. \& He, G.B. (2011) Spatial pattern of Stellera chamaejasme population in degraded alpine grassland in northern slope of Qilian Mountains, China. Chinese Journal of Ecology, 30,1312-1316.

Tan, Z.M. \& Zhou, S.C. (1995) Grassland degrading in Luolong County, Tibet. Journal of Sichuan Grassland, 1995, 25-28.

Toth, G., Hermann, T., Silva, M.R.D. \& Montanarella, L. (2018) Monitoring soil for sustainable development and land degradation neutrality. Environmental Monitoring and Assessment,190, 57.

Wang, C.T., Long, R.J., Wang, Q.J., Jing, Z.C. \& Shi, J.J. (2009) Changes in plant diversity, biomass and soil C, in alpine meadows at different degradation stages in the headwater region of three rivers, China. Land Degradation \& Development, 20, 187-198.

Wang, C.T., Wang, Q.J., Long, R.J., Jing, Z.C. \& Shi, H.L. (2004) Changes in plant species diversity and productivity along an elevation gradient in an alpine meadow. Acta Phytoecologica Sinica,28, 240-245.

Wang, F.S., He, Y.T., Shi, P.L., Niu, B., Zhang, X.Z. \& Xu, X.L. (2016) Stellera chamaejasme as an indicator for alpine meadow degradation on the Tibetan Plateau. Chinese Journal of Applied \& Environmental Biology, 22, 567-572.

Wang, H., Zhou, S.Q. \& Huang, Z.J. (2009) A study on allelopathic effect of Stellera chamaejasme L. on Melilotus suaveolens Ledeb and Lolium perenne L. Acta Agrestia Sinica, 17, 826-829.

Wang, H., Zhou, S.Q., Huang, Z.J., Liu, Y.L. \& Hu, H.F. (2008) A Study on Resistibility of Agropyron mongolicum against the Allelopathy of Stellera chamaejasme. Chinese Journal of Grassland, 30,110-112.

Wang, K. (2001) Effects of plant roots on soil anti-erosion. Soil and Environmental Sciences, 10, 250-252.

Wang, Y. (2004) Spatial distribution patterns and dispersal mechanisms of the seed population of Stellera chamaejasme on degraded grasslands in Inner Mongolia, China. Acta Ecologica Sinica . 
Wang, Y.X., Wang, Z.F., Cheng, Y.X. \& Hou, F.J. (2014) The roles of toxic and harmful grass in grassland agro-ecosystems.Pratacultural Science, 31, 381-387.

Wang, Y.Z. \& Gilbert, M.G. (2007) Stellera Linnaeus. In: Flora of China (ed. by Wu Z.Y., Raven P.H. and Hong D.Y.) . Science Press, Beijing.

Wei, C., Zhong, B., xU, L.Y., Du, L.F. \& Sun, G. (2017) Allelopathic effects of root aqueous extract of different age of Stellera chamaejasme on four common plants in alpine meadow of Tibet Plateau.Ecological Science, 36, 1-11.

Wong, S.K., Tsui, S.K., Kwan, S.Y., Aoli, S.X., Lin, R.C., Tang, L.M. \& Chen, J.X. (2004) Establishment of characteristic fingerprint chromatogram for the identification of Chinese herbal medicines. Journal of Food and Drug Analysis, 12, 110-114.

Wu, C.C., Han, T.S., Lu, H. \& Zhao, B.Y. (2016) The toxicology mechanism of endophytic fungus and swainsonine in locoweed.Environmental Toxicology and Pharmacology, 47, 38-46.

Wu, G.L., Du, G.Z., Liu, Z.H. \& Thirgood, S. (2009) Effect of fencing and grazing on a Kobresia-dominated meadow in the Qinghai-Tibetan Plateau. Plant and Soil, 319, 115-126.

Xin, L., Cui, J., Zhang, S.T., Zhang, W.G., Liu, Y.H., Liu, S.R. \& An, S.Q. (2012) Differential water uptake among plant species in humid alpine meadows. Journal of Vegetation Science, 24,138-147.

Xing, F., Gou, J. \& Wei, C. (2004) Judging method of individual age and age structure of Stellera chamaejasme population in degraded steppe. The Journal of applied ecology, 15, 2104-2108.

Xing, F. \& Song, R. (2002) Population distribution pattern and dynamics of poisonous Stellera chamaejasme on grassland. Pratacultural Science, 19, 16-19.

Yan, Z., Qiang, Wang, D.D., Cui, H.Y., Zhang, D.H. \& Yu, H. (2016) Phytotoxicity mechanisms of two coumarin allelochemicals from Stellera chamaejasme in lettuce seedlings. Acta Physiologiae Plantarum,38, 248.

Yan, Z.Q., Guo, H.R., Yang, J.Y., Liu, Q., Jin, H., Xu, R., Cui, H.Y. \& Qin, B. (2014) Phytotoxic flavonoids from roots of Stellera chamaejasme L. (Thymelaeaceae). Phytochemistry, 106, 61-68.

Yan, Z.Q., Zeng, L.M., Jin, H. \& Qin, B. (2015) Potential ecological roles of flavonoids from Stellera chamaejasme. Plant Signaling \& Behavior, 10 .

Yang, J.Y., Yan, Z.Q., Rui, X.U., Liu, Q., Jin, H., Cui, H.Y. \& Qin, B. (2011) Isolation of plant growth inhibitory components from the root of Stellera chamaejasme and function mechanism. Acta Botanica Boreali-occidentalia Sinica, 31, 291-297.

Zhang, H., Jin, H., Ji, L.Z., Tao, K., Liu, W., Zhao, H.Y. \& Hou, T.P. (2011) Design, synthesis, and bioactivities screening of a diaryl ketone-inspired pesticide molecular library as derived from natural products. Chemical Biology \& Drug Design, 78, 94-100.

Zhang, Q., Zhao, C.Z., Dong, X.G., Xiao-Li, M.A., Hou, Z.J. \& Yu, L.I. (2015a) Relationship between flower size and leaf size,number of Stellera chamaejasme population of degraded alpine grassland along an altitude gradient. Chinese Journal of Ecology, 34,40-46.

Zhang, Q., Zhao, C.Z., Ma, X.L., Hou, Z. \& Li, Y. (2013) Response of reproductive allocation of Stellera chamaejasme population in alpine grassland to altitude. Chinese Journal of Ecology, 32,247-252.

Zhang, Y.H., Volis, S. \& Sun, H. (2010) Chloroplast phylogeny and phylogeography of Stellera chamaejasme on the Qinghai-Tibet Plateau and in adjacent regions. Molecular Phylogenetics and Evolution, 57, 11621172 . 
Zhang, Y.H., Zhang, J.W., Li, Z.M. \& Sun, H. (2015b) Genetic diversity of the weed species, Stellera chamaejasme, in China inferred from amplified fragment length polymorphism analysis. Weed Biology and Management, 15, 165-174.

Zhang, Z.C., Yue, F.S. \& Qin, Y.C. (2004) Study on the Vegetation Community's Structure of Degraded Grassland in Qilian Mountains. Grassland of China .

Zhang, Z.C., Yue, F.S., Qin, Y.C. \& Xue bin, H.E. (2004) Study on vegetation community's structure of degraded grassland of noxious and miscellaneous grass type. Journal of Desert Research,24, 507-511.

Zhang, Z.Q., Zhang, Y.H. \& Sun, H. (2011) The reproductive biology of Stellera chamaejasme (Thymelaeaceae): A self-incompatible weed with specialized flowers. Flora, 206, 567-574.

Zhao, B.Y., Liu, Z.Y., Hao, L.U., Wang, Z.X., Sun, L.S., Wan, X.P., Guo, X., Zhao, Y.T., Wang, J.J. \& Shi, Z.C. (2010) Damage and Control of Poisonous Weeds in Western Grassland of China. Agricultural Sciences in China, 9, 1512-1521.

Zhao, C.Z., Gao, F.Y., Sheng, Y.P., Dong, X.G. \& Zhou, W. (2011) Fine-scale spatial distribution and spatial association of Stellera chamaejasme population. Arid Land Geography, 34,492-498.

Zhao, C.Z., Gao, F.Y., Wang, X.P., Sheng, Y.P. \& Shi, F.X. (2016) Fine-scale spatial patterns of Stellera chamaejasme population in degraded alpine grassland in upper reaches of Heihe, China.Chinese Journal of Plant Ecology, 34, 6080-6087.

Zhao, C.Z. \& Zhang, Q.P. (2010) The spatial pattern of soil seed bank of Stellera chamaejasme community in degraded grassland of the Qilian Mountains. Chinese Journal of Grassland, 32, 79-85.

Zhao, M.L., Gao, X.L., Wang, J., He, X.L. \& Han, B. (2013) A review of the most economically important poisonous plants to the livestock industry on temperate grasslands of China. Journal of Applied Toxicology, 33, 9-17.

Zheng, B.J. \& Hu, H.Q. (2006) Changes of flavonoids content in Stellera chamaejasme in Songnen grassland of Heilongjiang Province. Journal of Northeast Forestry University, 34, 59-60.

Zhou, S.Q., Huang, Z.J., Wang, H., Liu, Y.L. \& hU, H.F. (2009a) Research on Allelopathy of Stellera chamaejasme on Psathyrostachys juncea. Chinese Journal of Grassland, 31, 94-97.

Zhou, S.Q., Huang, Z.J., Wang, H., Liu, Y.L. \& Hui-Fang, H.U. (2009b) Allelopathic effect of Steura chamaejasme decomposing in soil on Onobrychis viciifolia. Pratacultural Science, 26, 91-94.

Zhou, S.Q., Wang, H., Huang, Z.J. \& Liu, Y.L. (2010) Allelopathy of Stellera chamaejasme on Elymus dahuricus. Grassland $\&$ Turf .

Ziska, L.H., Epstein, P.R. \& Schlesinger, W.H. (2009) Rising CO2, climate change, and public health: exploring the links to plant biology.Environmental Health Perspectives, 117, 155-158.

\section{Figure legends}

Figure 1 Global distribution of $S$. chamaejasme based on previously published records (Liu, Long \& Yao 2004; Wang 2004; Wang \& Gilbert 2007; Zhang, Volis \& Sun 2010; Zhao et al. 2010), primarily including southern Russia, North Korea, Mongolia, Nepal, and northern and southwestern China.

Figure 2 Plants, flowers, and landscapes of the toxic weed (S. chamaejasme ). (A): plants of S. chamaejasme in an alpine grassland; (B): plants of $S$. chamaejasme in a typical grassland; (C): S. chamaejasme outside the fence; (D): white flower of $S$. chamaejasme ; (E): landscape of $S$. chamaejasmein an alpine grassland; (F): landscape pattern of $S$. chamaejasmein a desert grassland taken by an unmanned aerial vehicle.

Figure 3 Conceptual graph of the adaptive strategies of toxic weeds for environmental stress (yellow background), competition from other plants (blue background), and animal disturbance (orange background). 
Fine dotted arrow $=$ impacts of environmental conditions; Thick blue dotted arrow $=$ intraspecific and interspecific relationships; Thick orange dotted arrow $=$ interactions between plant and animals.

Figure 4 The potential ecological effects of toxic weeds on grassland ecosystems (purple background), soil (yellow background), and co-existing plants (green background).

Figure 5 The processes of grassland succession. Grassland degrades as a result of climate change and human activities; Toxic weeds invade as a consequence of their many adaptations to disturbed environments; Degraded grassland recovers under the protection of toxic weeds from excessive destruction; Livestock and rats destroy degraded grasslands by the excessive removal of toxic weeds; The grassland ecosystem collapses and desertification occurs as a consequence of the excessive damage. Red solid arrows indicate the positive feedback loop with toxic weeds. Yellow dotted arrows indicate the negative feedback direction that occurs in the absence of toxic weeds.

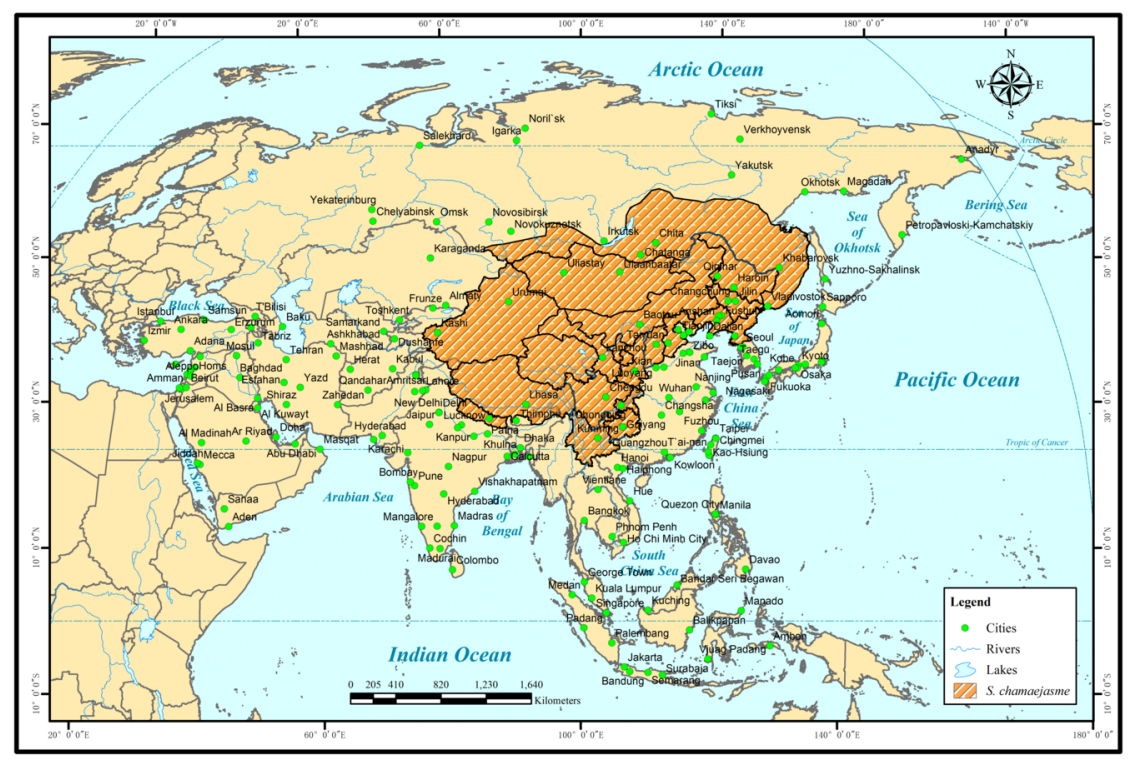

Fig. 1 


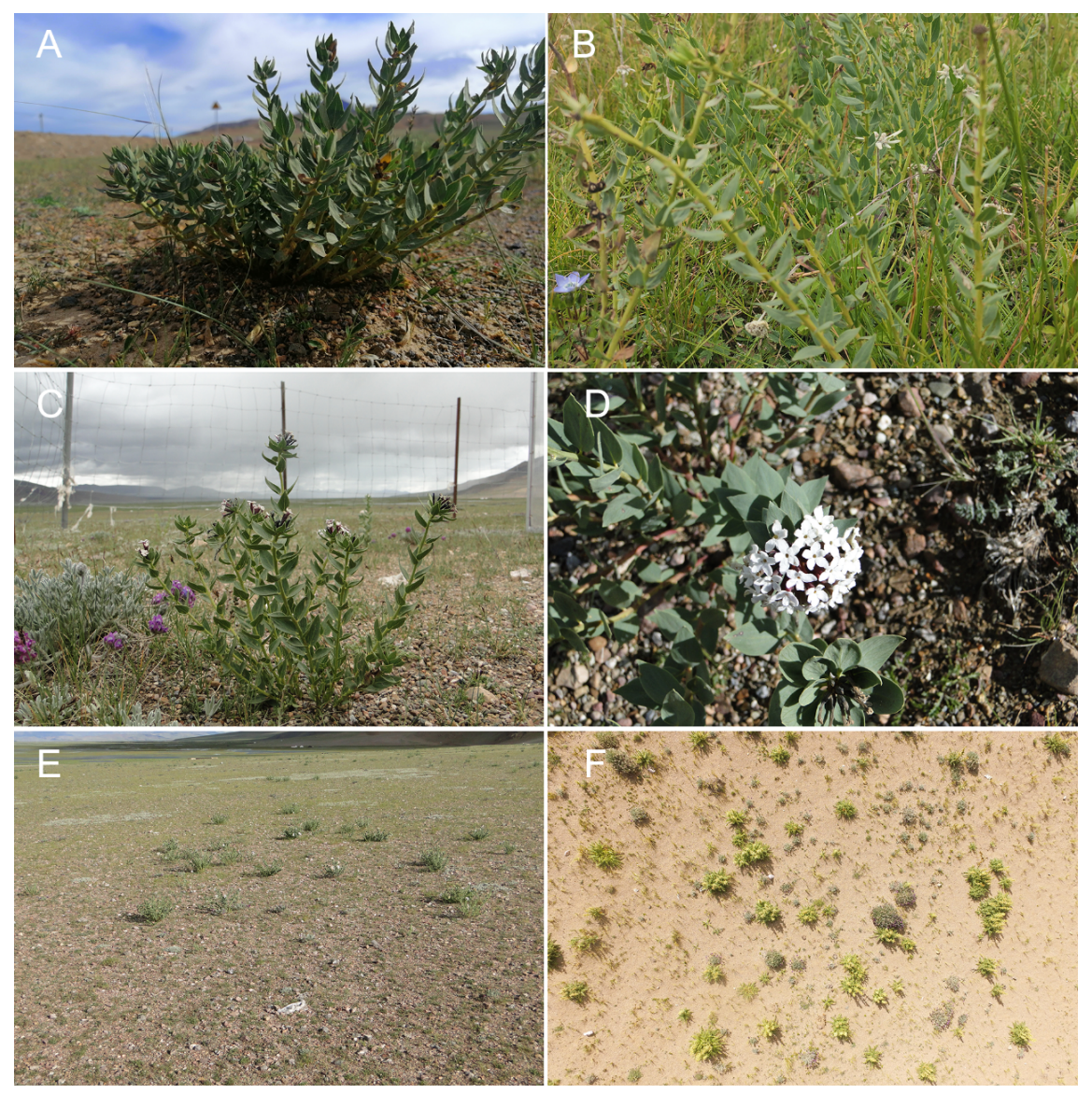

Fig. 2 


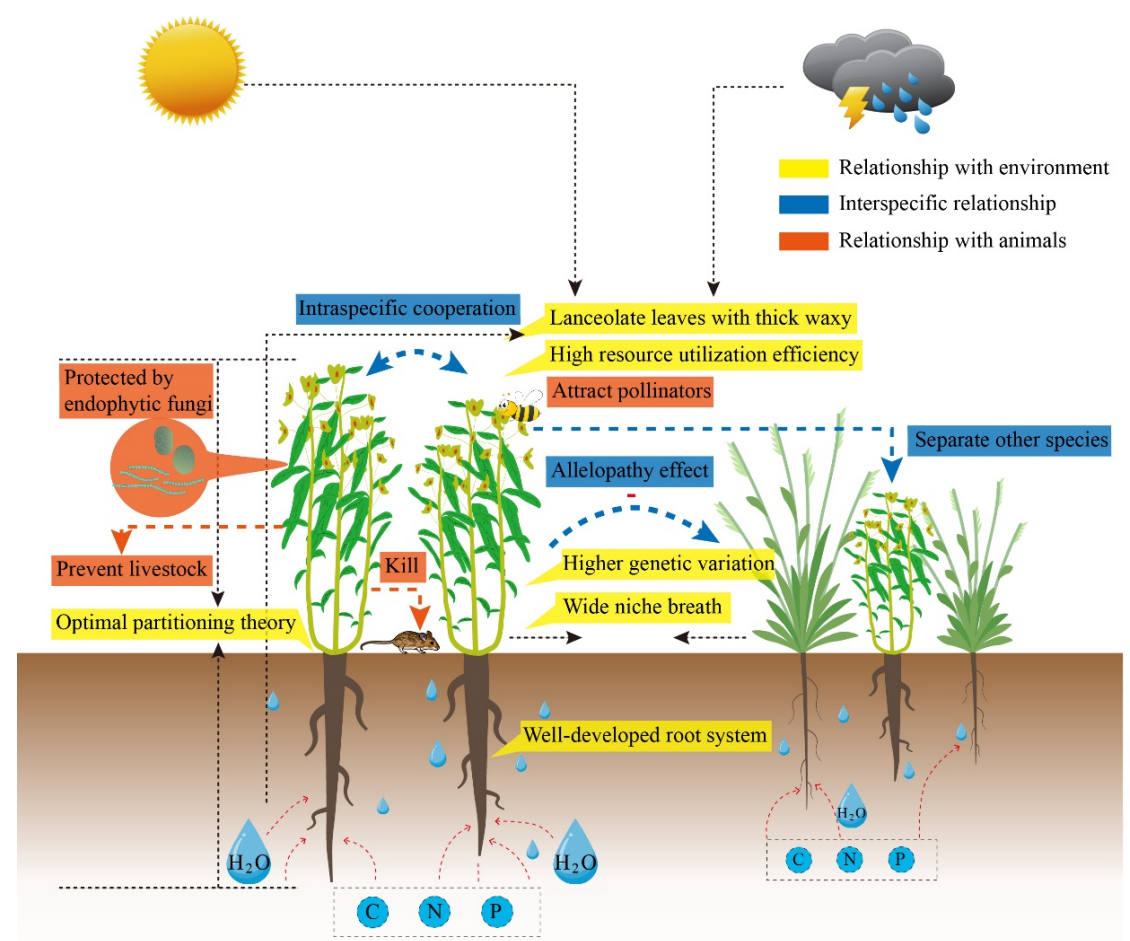

Fig. 3 


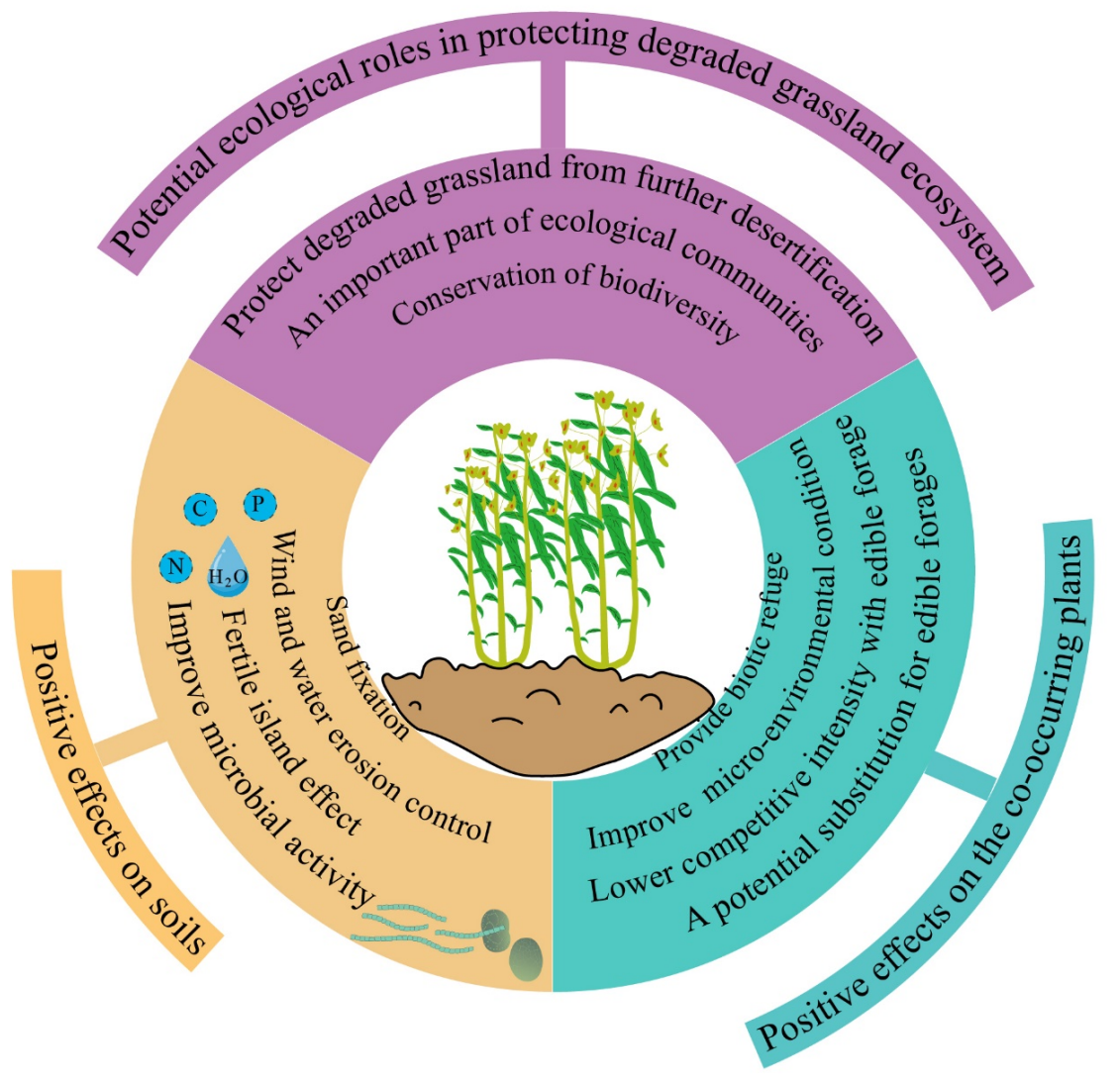

Fig. 4

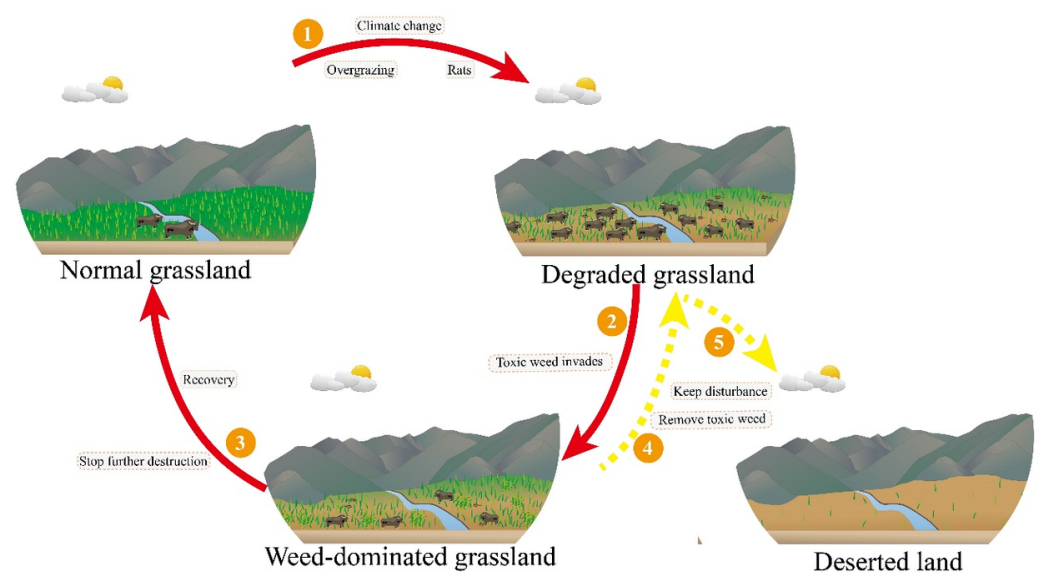

Fig. 5 